\title{
Physicochemical Characterizations and Antioxidant Property of Copaiba Oil Loaded into SNEDDS Systems
}

\author{
Denise P. Emerenciano, ${ }^{\circledR a}$ Bernardo B. D. Baracho, ${ }^{a}$ Melyssa L. de Medeiros, ${ }^{b}$ Hugo A. O. Rocha, ${ }^{c}$ \\ Francisco H. Xavier Jr., ${ }^{b}$ Valdir F. da Veiga Jr. ${ }^{d}$ and Maria Aparecida M. Maciel ${ }^{\oplus *, a, b}$ \\ ${ }^{a}$ Instituto de Química, Centro de Ciências Exatas e da Terra, \\ Universidade Federal do Rio Grande do Norte, 59072-970 Natal-RN, Brazil \\ ${ }^{b}$ Programa de Pós-Graduação em Biotecnologia, Universidade Potiguar, \\ Laureate International Universities, Campus Salgado Filho, 59075-000 Natal-RN, Brazil \\ 'Programa de Pós-Graduação em Biotecnologia (RENORBIO), Departamento de Bioquímica, \\ Universidade Federal do Rio Grande do Norte, 59072-970 Natal-RN, Brazil \\ ${ }^{d}$ Seção de Química, Instituto Militar de Engenharia, 22290-270 Rio de Janeiro-RJ, Brazil
}

Self-nanoemulsion drug delivery systems (SNEDDS) represent a potential carrier to improve solubility and bioavailability of health care products. In this sense, copaiba oil (CO) loaded on cosurfactant-free SNEDDS formulations (CO-SNEDDS) were obtained by using phase diagram performed on different concentrations of constituents (oil, surfactant and water). The CO-SNEDDS are composed of $1 \%(\mathrm{~m} / \mathrm{m})$ of oil phase, $20 \%(\mathrm{~m} / \mathrm{m})$ of Tween 80 , and $79 \%(\mathrm{~m} / \mathrm{m})$ of doubledistilled water. Specifically, varying the oil phase to $1 \%$ of CO affords the so-called SNECO system, and $1 \%$ of $\mathrm{CO}$ blended on a 1:1 ratio with coconut oil or sunflower oil affords, respectively, the SNECO-COO and SNECO-SO derivative systems. CO sample was authenticated by gas chromatography equipped with a flame ionization detector and the CO-SNEDDS samples were characterized by droplet particle size, zeta potential, polarized light microscopy, $\mathrm{pH}$, conductivity, refractive index, rheological and surface tension analyses. According to the antioxidant tests reducing power and hydroxyl inhibiting formation, the findings displayed 47.89 and $72.92 \%$ for SNECO, 46.48 and $84.11 \%$ for SNECO-COO, and 52.46 and $74.48 \%$ for SNECO-SO, respectively. From now on CO-SNEDDS based systems become available as promising targets for novel medicinal investigations and also could be undertaken for the oral administration of poorly water soluble drugs.

Keywords: Copaifera multijuga Hayne, copaiba oil, self-nanoemulsion drug delivery system, physicochemical characterization, antioxidant activity

\section{Introduction}

Free radicals are produced by many factors, such as physical effects, chemical reactions and metabolic processes, and play important roles in the homeostasis of organism. However, the uncontrolled oxidative stress from reactive oxygen species (ROS) can damage biomolecules inducing physiological damage to organism and indirectly causing severe diseases. ${ }^{1}$ Natural antioxidant agents showing low side-effect have been investigated to promote health benefit effects and represent an important target to replace synthetic compounds, but many of them are

*e-mail: mammaciel@quimica.ufrn.br suspected to promote liver damage and carcinogenesis. ${ }^{2,3}$ In this sense, the antioxidant activity of the natural copaiba oil-resin (Copaifera langsdorffii Desf.) was assayed in the in natura form and showed scavenging effects (2,2-diphenyl-1-picrylhydrazyl (DPPH), hydroxyl radical, and hydrogen peroxide). ${ }^{4}$

Copaifera species (family Leguminosae Juss., subfamily Caesalpinoideae Kunth) are native trees largely found in the tropical region of Latin America and West Africa. ${ }^{5}$ The oil-resin extracted from Copaifera species is usually known as copaiba oil (CO), and has a wide pharmacological application including antimicrobial, antinociceptive, antineoplastic, anti-inflammatory, wound healing, in the treatment of skin diseases such as psoriasis, eczema and 
dermatitis, besides use in diseases of the respiratory tract such as bronchitis and tonsillitis. ${ }^{5-10}$ The anti-inflammatory activity of CO extracted from different Copaifera species (C. multijuga Hayne, C. cearensis Huber ex Ducke and C. reticulata Ducke) is related to the terpene chemical composition consisting in a mixture of sesquiterpenes and diterpenes (labdane, clerodane and kaurane types) that showed large pharmacological properties. ${ }^{11}$

Despite CO therapeutic importance its bioavailability is limited by its poor solubility in water or biological solvents. ${ }^{12,13}$ In this sense, it is known that the bioavailability of organic compounds had been improved by using colloidal systems (nano- or microemulsion), which possess the ability to dissolve and load polar and nonpolar compounds, maintaining their molecular dispersion on controlled or sustained release, increasing the drug bioavailability, enhancing permeability and therapeutic functions. ${ }^{14-16}$ A colloid is a two phases system in which one phase is dispersed into a continuous phase, and is increasingly utilized to deliver bioactive chemicals and proved to contribute with the enhancement of long-term stability. ${ }^{16-19}$ Microemulsions are transparent, optically isotropic, and thermodynamically stable-phase transition systems. ${ }^{20,21}$ Nanoemulsions can be defined as an emulsion-type with uniform and small droplet sizes kinetically stable against sedimentation or creaming for a long period of time. ${ }^{22,23}$ However, phenomena such as Ostwald ripening, coalescence and phase separation associated with higher water content can be responsible to decrease the nanoemulsion stability during the storage by reducing the effectiveness of the dispersed phase. ${ }^{22}$ To overcome this drawback, self-nanoemulsion drug delivery systems (SNEDDS), an isotropic mixture of natural or synthetic oil and one or more hydrophilic surfactant (and also co-surfactants, if necessary), show metastable dispersions of nanodroplets of one liquid into higher amounts of water. This colloidal type system has a unique ability to form fine oil-in-water $(\mathrm{o} / \mathrm{w})$ nanoemulsions when mixed with aqueous media under mild agitation and temperature conditions, and provide many benefits, such as high stability, easy handling, enhanced solubility and oral bioavailability of health care products. ${ }^{15,16,23-27}$

In fact, the colloidal delivery type systems showed to be an important target on $\mathrm{CO}$ bioavailability. Rodrigues et al. ${ }^{26}$ for example, prepared a formulation comprising $5 \%(\mathrm{~m} / \mathrm{m})$ of CO, 5\% of surfactant blend (Span 80 and Tween 80 on $1: 1$ ratio), and $90 \%(\mathrm{~m} / \mathrm{m})$ of water in which a primary formulation was achieved at heating (around $70{ }^{\circ} \mathrm{C}$ ). According to mortality level caused by this formulation, against Aedes aegypti larvae, the concept of o/w nanoemulsion formulation containing $\mathrm{CO}$ may be used as a potential larvicidal. Meanwhile, Moraes et al. ${ }^{27}$ report the development of nanoemulsions based on copaiba and andiroba oils in order to test their effects against Leishmania infantum and L. amazonensis. The nanoemulsions were prepared using small amounts of water $(10 \mathrm{~mL})$ which was added to Tween $80(0.4 \mathrm{~g})$ under stirring and heating $\left(70^{\circ} \mathrm{C}\right)$; the oil phase ( $1 \mathrm{~g}$ of copaiba or andiroba oil) mixed with Span $80(0.4 \mathrm{~g})$ under agitation at $70{ }^{\circ} \mathrm{C}$; and the final homogenization was achieved using specific equipments. Xavier-Junior et al. ${ }^{28}$ by using predictive calculations of solubility parameters, formulated $\mathrm{o} / \mathrm{w}$ microemulsion with a high-volume ratio of copaiba essential oil $(5 \% \mathrm{~m} / \mathrm{m})$ and low surfactant content $(<5 \% \mathrm{~m} / \mathrm{m})$, either pure or in blends of Tween 20, Brij O10 and Pluronic. Stable colloidal systems containing CO $(5 \% \mathrm{~m} / \mathrm{m})$, surfactant blends of Span 80 and Tween 20 in aqueous medium, under agitation at $70{ }^{\circ} \mathrm{C}$, have been developed against Staphylococcus and Candida microorganisms related to skin diseases. ${ }^{12,29}$ Despite this, previous studies about the effect of self-colloidal drug delivery systems (SNEDDS or self-microemulsifying drug delivery system (SMEDDS)) based on copaiba oil-resin were not reported yet.

In the present study, three cosurfactant-free $\mathrm{o} / \mathrm{w}$ nanoemulsions formulations composed of low content of $\mathrm{CO}$ phase, a nonionic surfactant and large amount of water have been developed and then tested for antioxidant property. Specifically, CO (Copaifera langsdorffii Desf.) loaded into a polar self-nanoemulsion formulation produced a target SNEDDS-system called SNECO, which corresponds to a self-nanoemulsion system containing $1 \%(\mathrm{~m} / \mathrm{m})$ of $\mathrm{CO}$, $20 \%(\mathrm{~m} / \mathrm{m})$ of surfactant (Tween 80$)$, and $79 \%(\mathrm{~m} / \mathrm{m})$ of double-distilled water. Then, this principal system was modified varying the $\mathrm{CO}$ phase, but keeping contents of the emulsifier (Tween 80 ) and water phase, to afford two derivative SNEDDS cosurfactant-free formulations based on CO (CO-SNEDDS): self-nanoemulsion containing $1 \%(\mathrm{~m} / \mathrm{m})$ of a blend on $1: 1$ ratio of $\mathrm{CO}$ with coconut oil (COO) (SNECO-COO), and self-nanoemulsion containing $1 \%(\mathrm{~m} / \mathrm{m})$ of a blend on 1:1 ratio of $\mathrm{CO}$ with sunflower oil (SO) (SNECO-SO). These novel SNEDDS formulations based on CO (SNECO, SNECO-COO and SNECO-SO) were prepared in order to enhance the $\mathrm{CO}$-pharmacological bioavailability assayed at lower content, and herein were evaluated using in vitro antioxidant analyses.

\section{Experimental}

Materials

The copaiba oil-resin (Copaifera multijuga Hayne) was collected in Manaus, a voucher specimen (61212 INPA) is available at the Herbarium of National Institute for 
Amazonian Research. Coconut (COO) and sunflower (SO) oils were commercially obtained. Tween 80 , ferric chloride, ferrous sulfate heptahydrate $\left(\mathrm{FeSO}_{4} \cdot 7 \mathrm{H}_{2} \mathrm{O}\right)$, ethylenediamine-tetraacetic acid (EDTA), sodium salicylate, nitroblue tetrazolium (NBT), riboflavin and ascorbic acid (vitamin C) were purchased from SigmaAldrich. Potassium ferricianyde, ferrous sulfate and sulfuric acid were obtained from Merck. All other solvents and chemicals were of analytical grade.

\section{CO chemical characterization}

CO was analyzed in a gas chromatograph (GC) equipped with a flame ionization detector (FID) (Trace 1310, Thermo Scientific). The sample $(5.0 \mathrm{mg})$ was derivatized in situ using trimethylsilildiazomethane (TMSD), converting the diterpene carboxylic acids into the corresponding methyl esters. Split injections (1:20) were performed in a dimethylpolysiloxane column (DB-1; $25 \mathrm{~m} \times 0.25 \mathrm{~mm} \times 0.25 \mu \mathrm{m})$, using $\mathrm{He}$ as carrier gas at $2 \mathrm{~mL} \mathrm{~min}^{-1}$. Oven temperature was programmed from 120 to $150{ }^{\circ} \mathrm{C}\left(\right.$ at $\left.3{ }^{\circ} \mathrm{C} \mathrm{min}{ }^{-1}\right)$, followed by another heating ramp until $290{ }^{\circ} \mathrm{C}$, at $15{ }^{\circ} \mathrm{C} \mathrm{min}$. Detector and injector temperatures were set at 300 and $270^{\circ} \mathrm{C}$, respectively. Two standard mixtures were injected at this same condition: a homologous series of linear hydrocarbons from tridecane to heptadecane (C13 to $\mathrm{C} 17$ ), and a mixture containing the sesquiterpenes caryophyllene, humulene and caryophyllene oxide. The homologous series of hydrocarbons was applied to obtain the linear retention index (LRI) of the $\mathrm{CO}$ constituents, and then compared with literature. The mixture of the three sesquiterpenes, very common constituents of COs, were used to correct the LRI obtained and compare them with literature data. Mass spectrometry (MS) experiments were used to confirm the identification of the sesquiterpenes by comparing their mass spectra with automatic database (National Institute of Standards and Technology (NIST) $)^{30}$ and also to obtain the diterpene methyl esters MS. The MS data were compared with data from previously isolated substances from COs that were stored to compose a personal data library. Derivatized CO samples were injected into a GC (Trace CG Ultra, Thermo Scientific), coupled with MS detector (DSQ II, Thermo Scientific) with quadrupole analyzer and auto-injector (AI 3000, Thermo Scientific). MS were obtained by electron impact $(70 \mathrm{eV})$, from 40 to 400 a.m.u. and using a similar oven program from GC-FID: 120 to $150{ }^{\circ} \mathrm{C}$, at $2{ }^{\circ} \mathrm{C} \mathrm{min}{ }^{-1}$, followed by 150 to $260{ }^{\circ} \mathrm{C}$, at $15{ }^{\circ} \mathrm{C} \mathrm{min}-1$, and finally from 260 to $290{ }^{\circ} \mathrm{C}$, at $14{ }^{\circ} \mathrm{C} \mathrm{min}{ }^{-1}$. Samples were injected (split 1:40) using He as carrier gas at $2 \mathrm{~mL} \mathrm{~min}^{-1}$ in a Zebron ZB-5ms (Phenomenex; $20 \mathrm{~m} \times 0.18 \mathrm{~mm} \times 0.18 \mu \mathrm{m}$ ) column. The applied methodology is in accordance with our previous reported studies. ${ }^{31-34}$

\section{CO loaded into SNEDDS colloidal formulations}

The CO-SNEDDS were obtained by using phase diagram performed on different concentrations of constituents (oil, surfactant and water). Ternary phase diagram was constructed using the surfactant mass titration methodology into the aqueous and oily phases in order to obtain a polar $\mathrm{o} / \mathrm{w}$ microemulsion region. Phase diagrams were prepared with three different vegetable oil phases comprising $\mathrm{CO}$ and different oil blends on 1:1 ratio of $\mathrm{CO}$ mixed with coconut oil (Cocos nucifera L.) or CO mixed with sunflower oil (Helianthus annиus). The surfactant (Tween 80) was mixed with each specific oil phase, in the following mass ratios: 9:1, $8: 2,7: 3,6: 4,5: 5,4: 6,3: 7,2: 8$, and $1: 9$ of surfactant and oil phase, respectively. The surfactant and each oil phase were stirred and then diluted dropwise with double-distilled water and the ternary phase diagram regions of each CO-SNEDDS system were produced by using the mechanical stirring Vortex (IKA) finding separately the optimized homogenization under moderate temperature (5 min). Aiming to confirm the colloidal homogenization, each system (approximately $5 \mathrm{~mL}$ ) was charged to the centrifugation tube performed using accelerated centrifugation at $3500 \mathrm{rpm}$ for $15 \mathrm{~min}$ (Centribio 80-2B, Teknika).

Three CO-SNEDDS formulations were chosen from the ternary phase diagram by fixing the emulsifier and water contents $(20 \% \mathrm{~m} / \mathrm{m}$ of Tween 80 , and $79 \% \mathrm{~m} / \mathrm{m}$ of doubledistilled water, respectively) and varying the oil phase such as: (i) $1 \%(\mathrm{~m} / \mathrm{m})$ of CO affording the SNECO-target system; (ii) $1 \%(\mathrm{~m} / \mathrm{m})$ of a blend oil containing $0.5 \%$ of $\mathrm{CO}$ and $0.5 \%$ of coconut oil (COO) to afford the SNECO-COO system; and (iii) $1 \%(\mathrm{~m} / \mathrm{m})$ of a blend oil containing $0.5 \%$ of $\mathrm{CO}$ and $0.5 \%$ of sunflower oil (SO) for the SNECO-SO system. So, the CO-SNEDDS based colloidal systems are composed of $20 \%$ of Tween $80,1 \%$ of oil (CO or mixtures of CO on 1:1 ratio with coconut or sunflower oils) and $79 \%$ of doubledistilled water, under moderate heating $\left(55\right.$ to $\left.65^{\circ} \mathrm{C}\right)$. After physicochemical characterizations, the formulations were classified as nanoemulsion SNEDDS-type system.

Physicochemical characterization of the CO-colloidal systems

The CO-SNEDDS formulations named SNECO, SNECO-COO and SNECO-SO were characterized by using polarized light microscopy, $\mathrm{pH}$, conductivity, refractive index, droplet size, zeta potential, rheological behavior and surface tension analyses. The $\mathrm{pH}$ was measured by using a 
pre-calibrated $\mathrm{pH}$ meter (PG-2000, Gehaka) at $25 \pm 2^{\circ} \mathrm{C}$. The electrical conductivity of the samples was measured using a DM-32 conductivity meter (Digicrom Analytical) with a cell constant of $0.11 \mathrm{~cm}^{-1}$. The measurements were performed at $25 \pm 2{ }^{\circ} \mathrm{C}$. The refractive index of microemulsion samples were determined using an Abbe 5 refractometer (model D7 optical polarimeter, Bellingham plus Stanley) at $25 \pm 2{ }^{\circ} \mathrm{C}$.

The average droplet size and zeta potential were measured by a zeta potential analyzer (ZetaPlus, Brookhaven Instruments) using a detector angle of $90^{\circ}$. Samples were analyzed in a polystyrene cell at $25^{\circ} \mathrm{C}$. Rheological property was determined using oscillatory Haake Mars rheometer (Thermo Fisher Scientific; Z43 DIN 53018 cup and Z41 DIN 53018 rotor). The temperature was kept at $25.0 \pm 0.1{ }^{\circ} \mathrm{C}$ using a thermostatic bath. Analyses were carried out by applying a shear rate sweep from 0 to $10^{3} \mathrm{~s}^{-1}$. Surface tension was measured using a QC-6000 SensaDyne tensiometer employing the maximum pressure bubble technique, using nitrogen as gas phase. The results of the surface tension assays, expressed in $\mathrm{mN} \mathrm{m}^{-1}$ (or dyn $\mathrm{cm}^{-1}$ ), were analyzed with the SensaDyne tensiometer software, version 1.21.

\section{Antioxidant activity assays}

The in vitro antioxidant assays applied to the CO-SNEDDS formulations (SNECO, SNECO-COO and SNECO-SO) were performed by reducing power, hydroxyl radical scavenging, and superoxide radical scavenging, according to the methodologies previously described. ${ }^{35}$

\section{Reducing power}

The reducing power of the CO-SNEDDS formulations was quantified as previously described. Briefly, $4 \mathrm{~mL}$ of reaction mixture, containing $100 \mu \mathrm{L}$ of SNECO, SNECO-COO and SNECO-SO formulations in phosphate buffer $(0.2 \mathrm{M}, \mathrm{pH} 6.6)$, were incubated with potassium ferricyanide $(1 \% \mathrm{~m} / \mathrm{v})$ at $50^{\circ} \mathrm{C}$ for $20 \mathrm{~min}$. The reaction was stopped by trichloroacetic acid (TCA) solution $(10 \% \mathrm{~m} / \mathrm{v})$. The solution was then mixed with distilled water and ferric chloride $(0.1 \% \mathrm{~m} / \mathrm{v})$ solution and the absorbance was measured at $700 \mathrm{~nm}$. The result was expressed as a percentage of the activity shown by $0.2 \mathrm{mg} \mathrm{mL}^{-1}$ of vitamin $\mathrm{C}$, according to the methodologies previously described. ${ }^{36,37}$

\section{Hydroxyl radical scavenging}

The scavenging activity of the CO-SNEDDS formulations tested against the hydroxyl radical was investigated using Fenton's reaction:

$\mathrm{Fe}^{2+}+\mathrm{H}_{2} \mathrm{O}_{2} \rightarrow \cdot \mathrm{OH}+\mathrm{Fe}^{3+}+\mathrm{OH}^{-}$
These results were expressed as an inhibition rate. Hydroxyl radicals were generated using a modified method: ${ }^{38,39} 3 \mathrm{~mL}$ sodium phosphate buffer $(150 \mathrm{mM}$, pH 7.4), which contained $10 \mathrm{mM} \mathrm{FeSO} \cdot 7 \mathrm{H}_{2} \mathrm{O}, 10 \mathrm{mM}$ EDTA, $2 \mathrm{mM}$ sodium salicylate, $30 \% \mathrm{H}_{2} \mathrm{O}_{2}(200 \mu \mathrm{L})$ and $100 \mu \mathrm{L}$ of each sample (SNECO, SNECO-COO and SNECO-SO). In the control, a sodium phosphate buffer replacing $\mathrm{H}_{2} \mathrm{O}_{2}$ was used. The samples were incubated at $37^{\circ} \mathrm{C}$ for $1 \mathrm{~h}$, and the presence of the hydroxyl radical was detected by monitoring absorbance at $510 \mathrm{~nm}$.

\section{Superoxide radical scavenging}

The superoxide radical scavenging $\left(\mathrm{O}^{2-}\right)$ assay applied to the CO-colloidal formulations was based on the capacity of each sample (SNECO, SNECO-COO and SNECO-SO) to inhibit the photochemical reduction of NBT in the riboflavin-light-NBT system. Each $3 \mathrm{~mL}$ of reaction mixture contained $50 \mathrm{mM}$ phosphate buffer $(\mathrm{pH} 7.8$ ), $13 \mathrm{mM}$ methionine, $2 \mu \mathrm{M}$ riboflavin, $100 \mu \mathrm{M}$ EDTA, $75 \mu \mathrm{M} \mathrm{NBT}$, and $1 \mathrm{~mL}$ sample solution. The production of blue formazan was followed by monitoring the increase in absorbance at $560 \mathrm{~nm}$ after $10 \mathrm{~min}$ illumination from a fluorescent lamp. The entire reaction assembly was enclosed in a box lined with aluminum foil. Identical tubes with the reaction mixture were kept in the dark and served as blanks. ${ }^{40,41}$

\section{Results and Discussion}

Chromatographic and spectrometric analyses allowed to identify terpenes, sesquiterpenes and diterpene, as well as fatty acids, which were derivatized and analyzed as their respective methyl esters observed as their ester derivatives. The sesquiterpene fraction comprises about $73.1 \%$ of the oil and remaining constituents such as $\beta$-caryophyllene $(13.9 \%, 5.8 \mathrm{~min}), \beta$-bisabolene $(13.1 \%, 7.4 \mathrm{~min})$, $\alpha$-bergamotene (10.2\%, $6.0 \mathrm{~min}$ ), $\beta$-selinene (5.6\%) and $\alpha$-selinene $(5.3 \%)$ were also detected. About $16.9 \%$ of the oil corresponds to diterpenes, including the kauranes: kaur-16-en $(0.7 \%)$ and kaurenoic acid $(8.7 \%, 16.8 \mathrm{~min})$ and also the labdane polyaltic acid $(6.3 \%, 17.1 \mathrm{~min})$. About $10.5 \%$ of the oil corresponds to fatty acids derivatives, analyzed as their corresponding methyl esters, in which the main substances are oleic acid (3.9\%), linoleic acid (3.4\%), palmitic acid (2.0\%) and estearic acid (1.2\%), with similar amounts of saturated (palmitic and estearic acids, 3.2\%), monounsaturated (oleic acid, $3.9 \%$ ) and polyunsaturated fatty acids (linoleic acids, 3.4\%).

Stable and single-phase o/w-type nanoemulsions containing $\mathrm{CO}$ were produced by using $\mathrm{CO}$ (SNECO) or a mixture of $\mathrm{CO}$ with coconut or with sunflower oils 
(SNECO-COO and SNECO-SO, respectively). The phase diagrams of each CO-SNEDDS formulation were based on the proposed model of colloidal system formation designed by Winsor. The procedure used to obtain the Winsor IV (WIV) region in the ternary phase diagram was based on determination of the maximum solubility of the active matter (surfactant) in aqueous and oil phases, by means of mass titrations. According to this methodology, the mixture of several compounds with different physicochemical properties can generate various colloidal systems including spontaneous monophasic systems. ${ }^{13,16-21,42-48}$

The ternary phase diagrams of SNECO, SNECO-COO and SNECO-SO were obtained by using Tween 80, oil phase and water. Specifically, the samples were formulated by using $20 \%$ of surfactant (Tween 80 ), $1 \%$ of oil phase based on $\mathrm{CO}$, and $79 \%$ of double-distilled water, affording o/w colloidal systems obtained without cosurfactant need. Hence, the CO solubility and miscibility studies were conducted by ternary phase diagram to obtain the maximum drug loading per formulation (target system CO-SNEDDS) and to provide large self-emulsifying areas. Specifically, to prepare the CO-SNEDDS systems, precise amounts of oil phase and surfactant were mixed together using a magnetic bar at moderate temperature and speed (on a magnetic stirring plate), followed by addition of water. Both phases were gradually heated separately $\left(55\right.$ to $65^{\circ} \mathrm{C}$ ) and during the water drop by drop addition $(20 \mathrm{~min}$ for $10 \mathrm{~mL}$ of solution) the highest temperature was maintained.

The CO-colloidal systems remained isotopically stable after centrifuge procedure ( $3500 \mathrm{rpm}$ ) as well as by water dilution (upon thirty dilutions) ensuring no phase change. Comparatively, no significant difference was observed in the phase diagram region of the CO-SNEDDS target formulation and its derivatives SNECO-COO and SNECO-SO systems. Figure 1 shows a representative phase diagram of these formulations focusing on WIV and Winsor I (WI) regions. This likely occurs due to the spontaneous formation of such systems at low oil concentration, and high water/surfactant concentration; even under variation of the oil phase, there is no significant modification on the Winsor regions formation. The ratio of water/oil is an important factor in the formation and the stability of nanoemulsions, and the increase of droplet size caused by coalescence phenomena can be inhibited by using a biocompatible surfactant or surfactant blends. In fact, surfactant lowers the interfacial tension favoring the formation of interfaces. Hence, the emulsifier stabilizes the droplets by forming a membrane at the interface, which prevents coalescence causing a strong and elastic physical barrier enough to prevent the coalescence of dispersed droplets and also by reduction of the interfacial tension. When the interface is saturated with the surfactant molecules, self-assembly is formed and the surface tension reached its minimum value at the critical micellar concentration (CMC) and remains constant above it. ${ }^{13,49-51}$ Conventional emulsions are inherently unstable from physical standpoint and coalescence or flocculation cause phase separation, which is visually apparent and increase particle size, with droplets diameter ranging from 0.5 to $100 \mu \mathrm{m} .{ }^{31}$

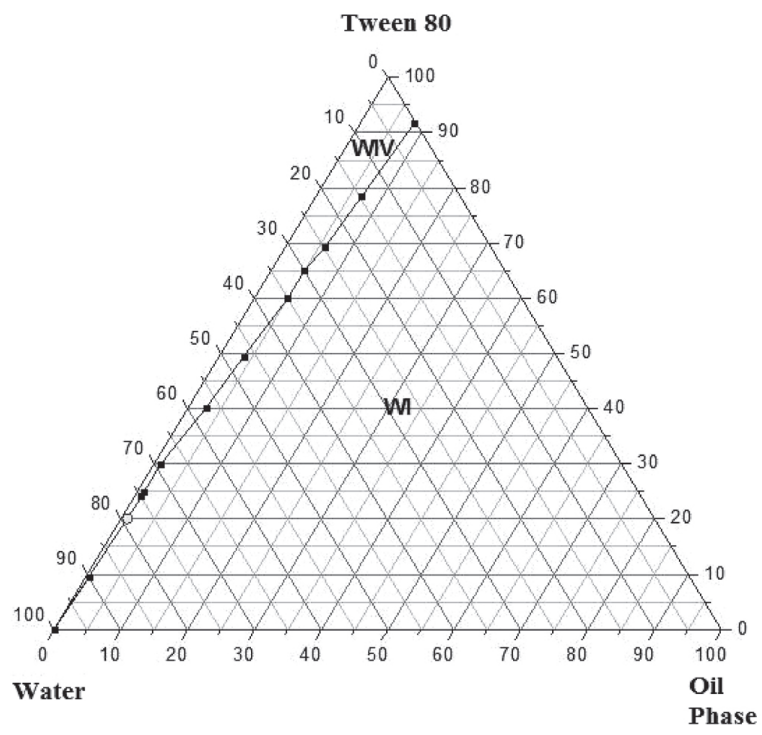

Figure 1. Ternary phases diagram of the CO-SNEDDS formulations.

In this work, cosurfactant-free emulsification of two phase mixtures composed of oil/Tween 80 (organic phase) and water (inorganic phase) with the objective to define low energy approaches by using water titration to construct the colloidal range for producing a self-colloidal drug delivery system based on CO (CO-SNEDDS) was then developed, either including higher $\mathrm{CO}$ loading capacity in a relatively simple manufacturing process, which is similar to the extreme emulsification approaches. ${ }^{15,16,51}$ In fact, the obtained CO-SNEDDS formulations (SNECO, SNECO-COO and SNECO-SO) showed to be stable over an extended time frame, keeping homogeneous, transparent and showed the Tyndall effect of colloidal dispersions. ${ }^{52}$ These systems also appeared homogenous by being observed through a light microscope with the phase contrast mode and were isotropic when observed under polarized light microscope consistently with usual optical properties as described for many stable colloidal dispersions. ${ }^{15,16,26,31}$

The phase diagram study allowed to choose the optimized target system which showed equaling viscous and gravitational forces acting on a $\mathrm{CO}$ droplet immersed in the aqueous continuous phase, reducing the density difference between the two phases (organic and inorganic). The biocompatible surfactant (Tween 80 ) under the 
colloidal developed approach inhibited coalescence process, creaming, and phase separation. The CO-SNEDDS target formulation and its derivatives SNECO-COO and SNECO-SO systems were submitted to measurements typically conducted in colloid science such as $\mathrm{pH}$, conductivity, refractive index, droplet size, viscosity, and surface tensions, whose results are summarized in Table 1. The colloidal characteristic of the CO-SNEDDS dispersions was confirmed by those experiments. A diluted CO-SNEDDS dispersion, for example, gives rise to the Tyndall effect in which a laser beam passing through a colloidal solution leaves a discernible track as a result of light scattering. This phenomenon is the effect of light scattering in colloidal dispersion, while showing no light in a common solution. ${ }^{52}$

The $\mathrm{pH}$ can influence significantly the stability of colloidal systems, due to the effect on the ionization and surface charges of droplets. ${ }^{53}$ Since the CO-SNEDDS formulations show slightly acid $\mathrm{pH}$ (6.10 and 6.28), they are appropriate for biological applications. In this sense, it is important to point out the phytochemical results of the CO sample, which shows a significant acid composition $(25.5 \%)$ such as kaurenoic acid $(8.7 \%)$, polyaltic acid $(6.3 \%)$ and $10.5 \%$ of fatty acids, in which the main substances are oleic acid (3.9\%), linoleic acid (3.4\%), palmitic acid $(2.0 \%)$ and estearic acid (1.2\%). Hence, finding slightly acid $\mathrm{pH}$ was only possible because the CO-SNEDDS formulations contain in the dispersed phase a small content $(1 \% \mathrm{~m} / \mathrm{m})$ of $\mathrm{CO}$.

Reinforcing this suggestion, Alencar et al. ${ }^{12}$ found strongly acidic $\mathrm{pH}$ on $\mathrm{CO}$ nanostructured colloidal formulations based on $5 \%(\mathrm{~m} / \mathrm{m})$ of CO (Copaiba langsdorffii Desf.) with a surfactant blend composition (Tween 20 and Span 80) for colloidal o/w nanostructured systems prepared by using high-energy approach (highpressure homogenizers and ultrasonic devices) known as phase invertion technique (PIT) methodology. The prepared formulations showed $\mathrm{pH}$ with values ranging from 3.22 to 3.48 , justified by the higher amounts of fatty acids. ${ }^{12}$ Meanwhile, Neves et al. ${ }^{54}$ observed pH 5.25 and 5.74 for $\mathrm{CO}$ droplet immersed in the oil continuous phase to form water-in-oil (w/o) microemulsion systems based on CO (Copaifera multijuga Hayne) comprising 47.1 or $39.0 \%(\mathrm{~m} / \mathrm{m})$ of water, concentrated oil phase $(6.1 \%)$ and a surfactant blend containing higher amounts of plurol oleique (18.3\%) and labrasol (36.6\%), suggesting that the surfactant fixed around the oil droplet interferes on the acidity of copaiba oil-resin components.

Concerning electrical conductivity this data represents an important parameter to characterize $\mathrm{o} / \mathrm{w}$ type system formation, which shows high conductivity values, confirming the external aqueous phase of the self-nanoemulsion systems. In fact, for SNECO, SNECO-COO and SNECO-SO, the observed conductivity varies from 204.8 to $215.6 \mu \mathrm{S} \mathrm{cm}^{-1}$. Reinforcing these data, the surface tension (Table 1) confirmed the o/w type system formation such as $47.93 \mathrm{dyn} \mathrm{cm}^{-1}$ (SNECO), $49.19{\mathrm{dyn} \mathrm{cm}^{-1}}^{-1}$ (SNECO-COO), and $47.49 \mathrm{dyn}_{\mathrm{cm}^{-1}}$ (SNECO-SO), which were quite close to the water tension values at the temperature of $25^{\circ} \mathrm{C}$.

Surface tension $\left(\right.$ dyn $\left.\mathrm{cm}^{-1}\right) v s$. concentration $\left(\mathrm{g} \mathrm{mL}^{-1}\right)$ of the surfactant Tween 80 showed lower surface tension for all CO-SNEDDS systems. The intersection point (Figure 2) resulted in the maximum dilution values of the micellar aggregates, such as: $8.837 \mathrm{~g} \mathrm{~mL}^{-1}$ (SNECO), $55.259 \mathrm{~g} \mathrm{~mL}^{-1}$ (SNECO-COO), and $16.701 \mathrm{~g} \mathrm{~mL}^{-1}$ (SNECO-SO), from which dispersed monomers are found below these values, and above them the self-nanoemulsion systems are formed.

The SNECO, SNECO-COO and SNECO-SO systems showed strong negative zeta potentials of $-1.41,-1.24$ and $-2.46 \mathrm{mV}$, respectively, allowing prediction of their electrical repulsion and attractive van der Waals forces, causing fast colloidal aggregation as a result of the attractive forces. ${ }^{55}$ According to Neves et al.,$^{54}$ the zeta potential data of CO load in microemulsion for example, could be a small number very close to zero due to the presence of nonionic surfactants (a blend containing plurol oleique and labrasol). The findings showed slightly negative zeta potentials such as -2.63 and $-3.57 \mathrm{mV}$ for two different nonpolar w/o type microemulsion systems, which were correlated to the solvation effect at the polar head group

Table 1. Physicochemical characterization of the CO-SNEDDS formulations

\begin{tabular}{lccccccc}
\hline Formulation & $\mathrm{pH}$ & $\begin{array}{c}\text { Conductivity / } \\
\left(\mu \mathrm{S} \mathrm{cm}^{-1}\right)\end{array}$ & $\begin{array}{c}\text { Refractive } \\
\text { index }\end{array}$ & $\begin{array}{c}\text { Droplet size / } \\
\mathrm{nm}\end{array}$ & $\begin{array}{c}\text { Zeta potential / } \\
\mathrm{mV}\end{array}$ & $\begin{array}{c}\text { Viscosity / } \\
\mathrm{cP}\end{array}$ & $\begin{array}{c}\text { Surface tension / } \\
\left(\text { dyn } \mathrm{cm}^{-1}\right)\end{array}$ \\
\hline SNECO & 6.10 & 215.6 & 1.490 & 0.91 & -1.410 & 7.4 & 47.93 \\
SNECO-COO & 6.28 & 204.8 & 1.483 & 5.87 & -1.240 & 6.7 & 49.19 \\
SNECO-SO & 6.28 & 215.0 & 1.481 & 6.94 & -2.460 & 7.4 & 47.49 \\
\hline
\end{tabular}

SNECO: CO loaded into a polar self-nanoemulsion formulation; SNECO-COO: self-nanoemulsion containing $1 \%$ (m/m) of a $1: 1$ blend of CO with coconut oil (COO); SNECO-SO: self-nanoemulsion containing $1 \%(\mathrm{~m} / \mathrm{m})$ of a 1:1 blend of $\mathrm{CO}$ with sunflower oil (SO). 
of the surfactant and also the presence of carboxylic acid groups in the copaiba oil-resin that are stabilized through a steric rather than stabilization by electrostatic effects. ${ }^{54}$
Comparatively, no matter the amount of water, similar zeta potentials $(-1.41$ to $-2.46 \mathrm{mV})$ were found in this present work, for the polar o/w CO-SNEDDS $(79 \%$ of
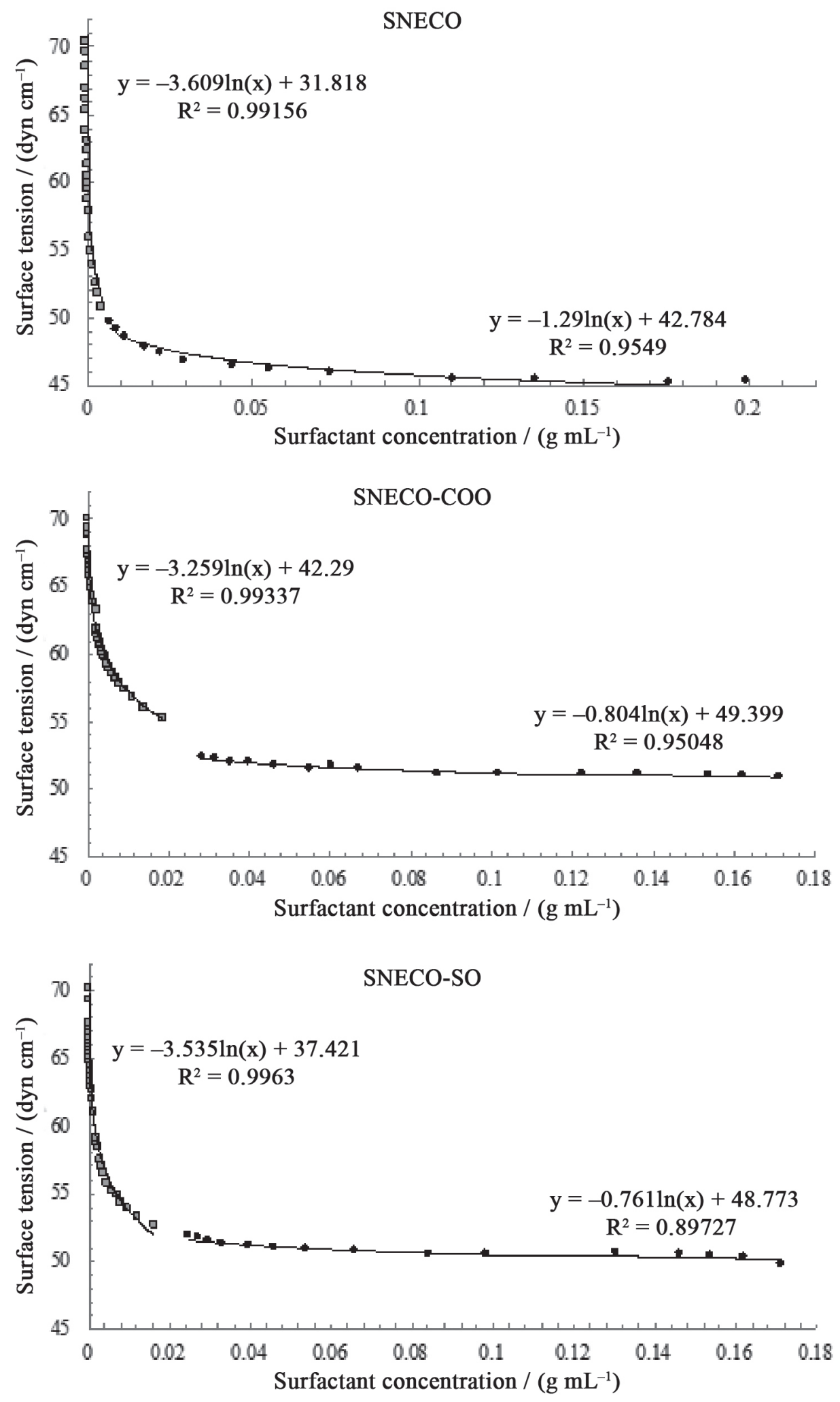

Figure 2. Representative graphics of surface tension vs. surfactant concentration of the CO-SNEDDS formulations. 
double-distilled water). According to Sharma et al. ${ }^{56}$ nonionic surfactant provides steric stabilization due to the presence of a dense hydrophobic tail and does not allow particles to come closer to one another, preventing particle agglomeration.

Considering all these results, it is mandatory to suggest that the ordered organization of building micellar blocks on the CO-SNEDDS nanostructures relies on specific molecular recognition compromised by: (i) combination of nonelectrostatic and noncovalent interactions (London forces or even dipole-dipole hydrogen bonds, since the water contents do not influence the observed values of zeta potential, above explained); (ii) van der Waals forces (permanent dipole-permanent dipole) occurring between $\mathrm{CO}$ acidic components and the nonionic surfactant; (iii) steric interactions (reduce repulsive forces between two particles); and ( $i v$ ) thermal forces. Concerning higher zeta potential values $(>30 \mathrm{mV})$, due to electrostatic repulsion, particle aggregation do not occur for charged particles. However, this rule cannot strictly be applied for systems containing steric stabilizers, because their absorption will decrease the zeta potential due to the shift in the shear plane of the particle..$^{55-58}$

According to Yan et al. ${ }^{58}$ although individually these forces are relatively weak, when combined as a whole, they can govern the self-assembly of molecular building blocks into superior and ordered structures. Then, the individual forces are also not strong compared to the thermal forces, which enable variations of structures and properties by a small variation of oil and surfactant parameters.

Concerning the CO-SNEDDS systems, since $\mathrm{CO}$ has a significant acid composition, van der Waals attractive forces between $\mathrm{CO}$ acidic components and Tween 80 molecules may act decreasing the zeta potential. In this sense, according to Hamaker molecular theory, ${ }^{59}$ the strength of the interaction increases according to the chemical differences between the particles and the dispersion medium, e.g., attraction between nonpolar particles in a polar medium, that is stronger than that of polar particles in a polar medium. ${ }^{59,60}$

The Hamaker molecular theory is in agreement with the zeta potential findings for CO-SNEDDS formulations $(-1.41$ to $-2.46 \mathrm{mV}$ by using $20 \%$ of the nonionic Tween $80)$, as well as with the zeta potential values -2.63 and $-3.57 \mathrm{mV}$ found by Neves et al. ${ }^{54}$ who used a blend of nonionic surfactants (in $\mathrm{m} / \mathrm{m}$ ): plurol oleique $(8.5 \%)$, labrasol $(33.8 \%), \mathrm{CO}(10.6 \%)$ and water $(47.1 \%)$, or even plurol oleique $(18.3 \%)$, labrasol $(36.6 \%)$, CO (6.1\%) and water $(39.0 \%)$. Reinforcing the validation of the Hamaker molecular theory, Alencar et al., ${ }^{12}$ on a lowest blend emulsifier composition, found a higher value of zeta potential ranging from -11.86 to $-34.37 \mathrm{mV}$ comprising $1.56 \%(\mathrm{~m} / \mathrm{m})$ of Tween $20,0.4 \%$ of Span $80,5 \%$ of CO (Copaiba langsdorffii Desf.) and large amount of water (93\%), by using a high-energy methodology and varying the $\mathrm{CO}$ form. In that, it is also important to point out the $\mathrm{pH}$ acidity (3.22 to 3.48) correlated to the higher amounts of $\mathrm{CO}(5 \% \mathrm{~m} / \mathrm{m})$ and its fatty acids. ${ }^{12}$ Hence, those results reinforce the suggestion of the occurrence of van der Waals attractive forces that could be expanded according to the increase of the surfactant content, resulting in lowest negative zeta potential values.

However, it was previously predicted that the minimum distance between the surfaces of two inorganic cores is typically found to be smaller than two times the length of the stabilizing molecules, which means that the shells of organic stabilizing molecules can partially penetrate each other. ${ }^{61,62}$ In this sense, Pellegrino et al. ${ }^{63}$ explained that there are two strategies to stabilize nanoparticles in aqueous solution, which are based on the introduction of charge. Nanoparticles of similar charge repel each other and thus aggregation is prevented. In fact, in electrolytic solution, charges are screened by counter ions and the electrostatic repulsion is weakened, which at sufficiently high salt concentrations finally can yield to particle aggregation. Thus, particle stabilization by electrostatic repulsion is only possible for moderate salt concentrations. Furthermore, the charge of stabilizing molecules depends on the $\mathrm{pH}$ value of the solution. For $\mathrm{pH}$ value above 5 to 6 , carboxy groups $(\mathrm{COOH})$, for example, become negatively charged $\left(\mathrm{COO}^{-}\right)$, whereas they are neutral for $\mathrm{pH}$ below 5-6. So, nanoparticles stabilized by the charge of carboxy groups are therefore only stable under neutral and alkaline $\mathrm{pH}$ conditions. On the other hand, steric repulsion also stabilizes nanoparticles formulations.

In this context, according to McClements, ${ }^{16}$ the van der Waals and hydrophobic interactions are attractive, whereas the steric and electrostatic interactions are usually repulsive. Specifically, the steric interactions are strong short range repulsive interactions, in which magnitude and range of the electrostatic repulsion depend on the electrical charge on the droplets and the ionic composition of the aqueous phase, and tend to increase with droplet size.

Nanoemulsions have very large specific surface area and because of that any chemical degradation occurs at the oil-water interface, such as lipid oxidation, but do not scatter light strongly, hence are highly stable to gravitational separation and droplet aggregation and can be designed as metastable dispersions systems and may be used to extend the shelf life of commercial products. ${ }^{16,64,65}$ Conventional emulsions have often nanoscale droplets in the range of $50-500 \mathrm{~nm}$, which fall into the 5 to $200 \mathrm{~nm}$ in transparent 
or semi-transparent nanoemulsion range and become milky opalescent up to $500 \mathrm{~nm} .{ }^{64}$ In this sense, the CO-SNEDDS formulations exhibited strongly small droplet sizes of 0.91 , 5.87, and $6.94 \mathrm{~nm}$, as well as similar lower viscosities of 7.4, 6.7, and 7.4 cP for SNECO, SNECO-COO, and SNECO-SO systems, respectively (Figure 3), indicating that these self-nanoemulsion systems are metastable dispersions of nanodroplets of one liquid (oil phase and Tween 80) into water medium..$^{65}$

Rheology behavior is a fundamental approach to provide useful information about the consistency or fluidity of colloidal systems, as well as indicate micellar aggregates performance over time. ${ }^{66}$ Figure 3 presents the rheology behavior of the SNECO, SNECO-COO, and SNECO-SO formulations. As revealed by the flow curves, the CO-SNEDDS formulations showed a linear relationship between shear stress and shear rate, characteristic of Newtonian flow, which is very important for convenient handling of commercial applications. The viscosities found here were very low $(<7.4 \mathrm{cP})$, near the value of water, owing to the external character of nano- or microemulsion systems.

Loewenberg and Hinch, ${ }^{67}$ studying the coalescence of real drop $(\mathrm{Ca}>0)$, concluded that van der Waals attraction is required for coalescence tendency, which is greatest when drops are pressed together by the shear flow. For a range of order-one viscosity ratios and $\mathrm{Ca}=0(1)$ drops, the tendency of coalescence is greatest when closely space drops are pulled apart in the extensional quadrant of the flow field. For $\mathrm{Ca}<0(1)$, drops behave like spherical drops that are stabilized against coalescence by a singular shortrange repulsion. These results were obtained by scaling arguments and illustrated by numerical calculations, in which $\mathrm{Ca}$ is a function of the continuous phase viscosity, imposed shear rate, undeformed drop radius, and interfacial tension. In this sense, notably this last parameter (interfacial tension) was evaluated (but not cited by the referred authors) for nonionic surfactant mixtures of different Span 20, 40, 60, and 80 blended with Tween 80 , and results showed that small droplet size provides increased stability against coalescence, sedimentation, and flocculation. ${ }^{17}$ Additionally, when the emulsions are colloidally stable, the flow curves usually exhibit a constant value of apparent viscosity at low shear rates. ${ }^{15}$

Concerning the CO-SNEDDS formulations, the dispersed phase displays a very small size droplet and the above undesirable characteristics were not observed even when accelerated stability test was performed, comprising abnormal conditions such as: (i) thermal stress test $\left(80-90{ }^{\circ} \mathrm{C}\right)$ up to the low energy applied $\left(55\right.$ to $\left.65^{\circ} \mathrm{C}\right)$ to produce the SNECO, SNECO-COO and SNECO-SO systems; followed by (ii) centrifugation test for a long period of time (1 h); (iii) water dilution (upon 30 dilutions) and then a new thermal stress followed by centrifugation test; and (iv) no change on droplet size distribution, turbidity, phase separation, Ostwald ripening (OR), homogeneous aspect and Tyndall effect were observed during six months storage $\left( \pm 10^{\circ} \mathrm{C}\right.$, or domestic refrigerator temperature).

For nanoemulstions, the OR phenomenon is the major source of instability, and involves large droplets growing at the expense of small ones; as a consequence, the more monodispersed the droplets, the less the nanoemulsion will be affected by OR. Besides, droplet size and droplet size distribution are the main factors influencing the properties of the product, such as rheology, appearance, chemical reactivity, stability and physical properties..$^{15,16,68-70}$

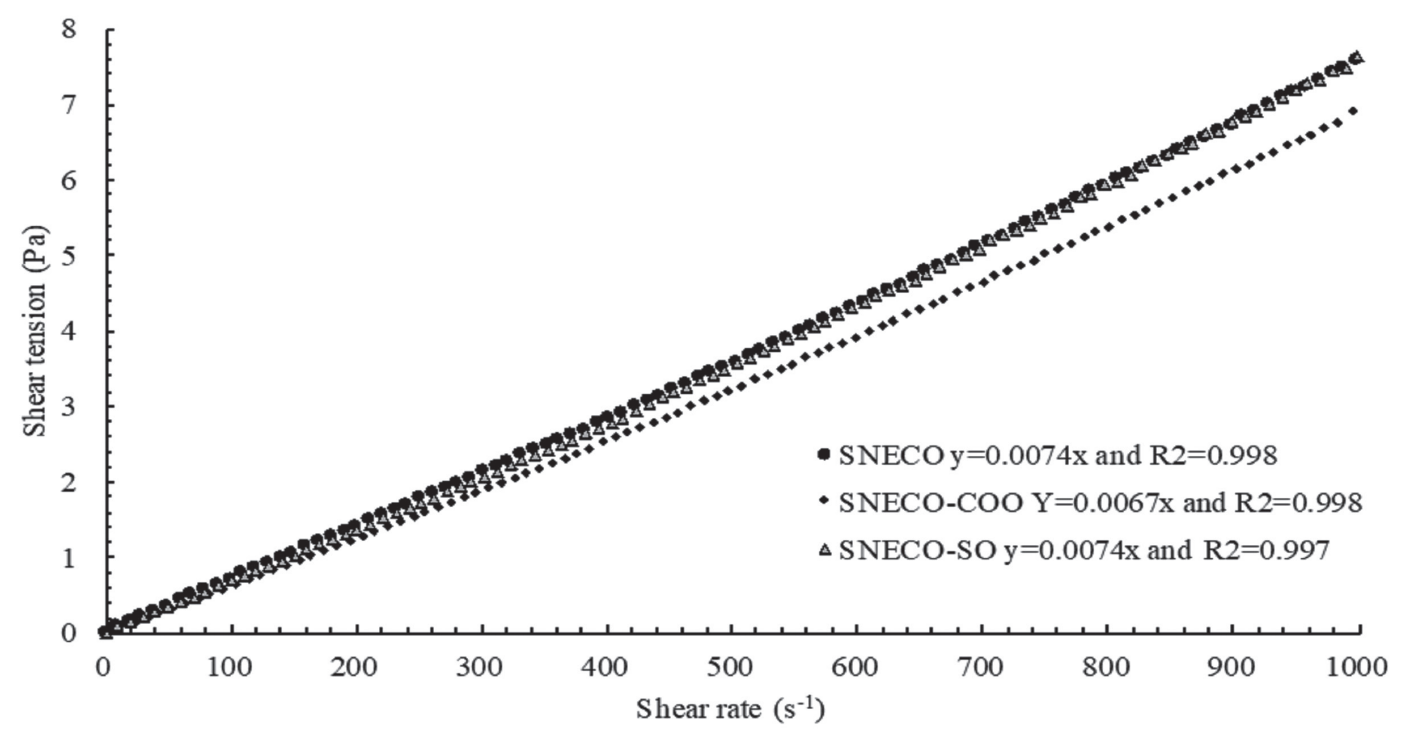

Figure 3. Representative graph of rheological behavior of the CO-SNEDDS formulations. 
According to Kaviani et al. ${ }^{64}$ systems that show no significant phase separation after several months were able to produce long term stable emulsions with great energy saving, due to low energy mixing requirement for emulsification process. As for example, several cosmetics and pharmaceuticals according to transparency, solution stability and droplet characteristics. In this sense, the COSNEDDS formulations are proposed for health benefits due to the capacity to prevent oxidative damage, which is the major cause of various diseases.

The antioxidant properties of the CO-SNEDDS formulations were evaluated by using in vitro assays such as reducing power, hydroxyl radical scavenging, and superoxide radical scavenging $\left(\mathrm{O}^{2-}\right)$. The assayed SNECO, SNECO-COO and SNECO-SO samples showed a reducing power corresponding to around $50 \%$ of the antioxidant activity of ascorbic acid $\left(1.0 \mathrm{mg} \mathrm{mL}^{-1}\right)$, used as reference drug (Table 2). Comparatively, the SNECO-SO formulation showed the highest reduction power $(52.46 \%)$ followed by SNECO (47.89\%) and SNECO-COO (46.48\%). The inhibition percentage of the SNECO-SO derivative system was found to be more compatible with the antioxidant property of ascorbic acid, which was used as standard antioxidant, and it was found according to equation 2:

Reducing power $(\%)=\left(\mathrm{A}_{1}-\mathrm{A}_{0} / \mathrm{A}_{2}-\mathrm{A}_{0}\right) \times 100$

where $\mathrm{A}_{0}$ is the absorbance of the blank solution, $\mathrm{A}_{1}$ is the absorbance of each CO-SNEDDS formulation, and $\mathrm{A}_{2}$ is the reference absorbance of ascorbic acid. The absorbance was measured at $700 \mathrm{~nm}$ and the results were expressed as a percentage of the activity shown by ascorbic acid, according to the methodologies previously described. ${ }^{36,37}$

The hydroxyl radical is a powerful oxidant, having a standard reduction potential. In this sense, Fenton type reactions are used to generate $\bullet \mathrm{OH}$ and the main reactions are according to equation 1 , where reaction of iron(II) with hydrogen peroxide $\left(\mathrm{H}_{2} \mathrm{O}_{2}\right)$ in aqueous solution leads to the formation of a hydroxyl radical $(\bullet \mathrm{OH}){ }^{38,39}$ In this work, the inhibition of hydroxyl radical formation was performed from the Fenton reaction, and the presence of the hydroxyl radical was detected by monitoring absorbance at $510 \mathrm{~nm}$. The greater inhibitory activity $(84.11 \%)$ was found for SNECO-COO (Table 2). Meanwhile, inhibition of superoxide radical formation did not present detectable results. These findings reinforce the in vitro scavenging effects (DPPH, hydroxyl radical, and hydrogen peroxide) of $\mathrm{CO}$ previously assayed in the in natura form. ${ }^{4}$

Recent development in medicinal field reports a number of disease associated with free radicals, in which oxidative stress is linked with many pathologies, particularly as treatments for stroke, cancer and neurodegenerative disorders. Molecular oxygen reached both benign and malign properties. The oxidant toxicity is largely due to the intermediates of oxygen reduction, e.g., $\mathrm{H}_{2} \mathrm{O}_{2}, \cdot \mathrm{OH}$, and $\mathrm{O}_{2}^{-}$, so, antioxidant protective effect encompasses defense against those species and any derived radical species. Different antioxidants agents, when used in combination, provided synergistic action and enhanced the therapeutic effect as compared to individual antioxidant. However, the clinical drugs that lower oral bioavailability become such a problem. ${ }^{71}$ Nanocarriers, on account of their higher ratio of surface area to volume, show improved pharmacokinetics and biodistribution of therapeutics, and because of their preferential accumulation at the target site, minimize toxicity. They can be used to deliver the drug to the central nervous system owing to their smaller size and higher permeability. ${ }^{72}$ Gastrointestinal tract is probably one of the locations that antioxidants such as polyphenols can act because they are not hindered by pharmacokinetic limitations. ${ }^{73}$ So, new antioxidant therapies should be developed taking into consideration the main reasons for the failure of the clinical interventions performed so far, including the limitations of poor drug solubility and high concentrations on gastrointestinal tract, which make these compounds unrealistic to be present at their effective levels in the target tissues. ${ }^{73-75}$ In this sense, it is important to point out that SNEDDS systems enhance the emulsification process upon dilution in aqueous medium and sustain droplets stability; under mild gastrointestinal peristalsis, spontaneously form an o/w emulsification and cause rapid absorption across the intestine. ${ }^{53}$

Table 2. Antioxidant activity of the CO-SNEDDS formulations

\begin{tabular}{lccc}
\hline Formulation & Reducing power / $\%$ & $\begin{array}{c}\text { Hydroxyl radical scavenging } \\
\text { activity / } \%\end{array}$ & \begin{tabular}{c} 
Superoxide radical scavenging activity / \% \\
\hline SNECO
\end{tabular} $4^{47.89 \pm 0.00}$ \\
SNECO-COO & $46.48 \pm 0.01$ & $72.92 \pm 0.01$ & ND \\
SNECO-SO & $52.46 \pm 0.00$ & $74.11 \pm 0.01$ & ND \\
\hline
\end{tabular}

SNECO: CO loaded into a polar self-nanoemulsion formulation; SNECO-COO: self-nanoemulsion containing $1 \%$ ( $\mathrm{m} / \mathrm{m}$ ) of a $1: 1$ blend of CO with coconut oil (COO); SNECO-SO: self-nanoemulsion containing $1 \%(\mathrm{~m} / \mathrm{m})$ of a 1:1 blend of CO with sunflower oil (SO); ND: not detected. 
Based on this background, the main innovative findings of this study are the promising CO-SNEDDS targets for novel medicinal investigations and that could also be undertaken for the oral administration of poorly water-soluble drugs. Additionally, among the various natural antioxidants, those systems carrying small amounts of $\mathrm{CO}(1 \% \mathrm{~m} / \mathrm{m}$; cosurfactant-free) show advantage for drug absorption after oral delivery with very promising pharmacodynamics effects, without risk of acute toxicity effects.

\section{Conclusions}

Sesquiterpenes, diterpenes and fatty acids were identified in $\mathrm{CO}$ (Copaiba multijuga Hayne) by using GCMS analyses, which show $73.1 \%$ of sesquiterpenes, $16.9 \%$ of diterpenes, and $10.5 \%$ corresponding to fatty acids. The CO-based systems were prepared aiming at CO-oral bioavailability and their pharmacological optimized uses. Non-toxic compounds were used to prepare CO-colloidal formulations (SNECO, SNECO-COO and SNECO$\mathrm{SO}$ ), which were characterized by using polarized light microscopy, $\mathrm{pH}$, conductivity, refractive index, droplet size, rheological behavior and surface tension analyses. The COSNEDDS formulations were prepared without cosurfactant aiming at gradual and prolonged $\mathrm{CO}$ release for oral or topical route, justifying its foremost importance for $\mathrm{CO}$ applied on lower content as promising target systems for general therapeutic applications. In fact, the copaiba resinoil was loaded in small amount $(1 \% \mathrm{~m} / \mathrm{m}$ of oil phase) with a high dilution factor, without losing its physicochemical properties. Coconut (COO) and sunflower (SO) oils were co-encapsulated with $\mathrm{CO}$, favoring a more suitable oil phase, which can afford new o/w nano- or microemulsion systems by new changes in the oil phase composition.

Comparatively, no significant difference was observed in the phase diagram region of SNECO, SNECO-COO and SNECO-SO. For all CO systems the refractive index confirmed the o/w type colloidal formation. After water dilution (upon 30 dilutions), these bioformulations remained isotopically stable, ensuring no phase change and characterizing them as SNEDDS. The lower modular value of zeta potential allowed to predict that their physic stability is correlated with steric rather than between the polar head group of the nonionic surfactant and the carboxylic acid groups present in the copaiba oil-resin, instead of stabilization by electrostatic effects largely observed in systems containing cosurfactant and/or ionic surfactants.

The antioxidant in vitro tests demonstrated good results with greater inhibitory activity for SNECO-COO system $(84.11 \%)$ by using hydroxil radical scavenging test. Meanwhile, the SNECO-SO formulation showed higher reduction power $(52.46 \%)$. These findings suggest that $\mathrm{CO}$ co-encapsulated with other oils favors a more suitable oil phase, which showed the best antioxidant results. So, from this approach by changing the oil phase composition and/or the surfactant content, and even adding a cosurfactant agent or blend of surfactants, the CO-SNEDDS target system may afford new biological o/w emulsion, nanoemulsion, and microemulsion systems, as well as novel SNEDDS or SMEDDS based on CO, which could be extensively applied to new therapeutics studies.

\section{Acknowledgments}

We would like to express sincere appreciation and deep gratitude to all participants in this work and CAPES/UFRN for financial support.

\section{References}

1. Schulz, T. J.; Zarse, K.; Voigt, A.; Urban, N.; Birringer, M.; Ristow, M.; Cell Metab. 2007, 6, 280.

2. Halliwell, B.; Biochem. Soc. Trans. 2007, 35, 1147.

3. Ronald-Prior, L.; Wu, X.; Am. J. Biomed. Sci. 2013, 5, 126.

4. Gelmini, F.; Beretta, G.; Anselmi, C.; Centini, M.; Magni, P.; Ruscica, M.; Cavalchini, A.; Facino, R. M.; Int. J. Pharmacol. 2013, 440, 170 .

5. Veiga Jr., V. F.; Pinto, A. C.; Quim. Nova 2002, 25, 273.

6. Zoghbi, M. G. B.; Andrade, E. H. A.; Silva, R. C. V. M.; Trigo, J. R.; J. Essent. Oil Res. 2009, 21, 501.

7. Leandro, L. M.; Vargas, F. S.; Barbosa, P. C.; Neves, J. K.; Silva, J. A.; Veiga-Junior, V. F.; Molecules 2012, 17, 3866.

8. Estevão, L. R.; Medeiros, J. P.; Baratella-Evêncio, L.; Simões, R. S.; Mendonça, F. S.; Evêncio-Neto, J.; Acta Cir. Bras. 2013, 28,863 .

9. Santos, A. O.; Izumi, E.; Ueda-Nakamura, T.; Dias-Filho, B. P.; Veiga-Júnior, V. F.; Nakamura, C. V.; Mem. Inst. Oswaldo Cruz 2013, 108, 59.

10. Lama, R.; Zhong, B.; Kulman, D. G.; Su, B.; Phytochem. Lett 2014, 10, 65 .

11. Veiga Jr., V. F.; Rosas, E. C.; Carvalho, M. V.; Henriques, M. G. M. O.; Pinto, A. C.; J. Ethnopharmacol. 2007, 112, 248.

12. Alencar, E. N.; Xavier-Júnior, F. H.; Morais, A. R. V.; Dantas, T. R. F.; Dantas-Santos, N.; Verissimo, L. M.; Rehder, V. L. G.; Chaves, G. M.; Oliveira, A. G.; Egito, E. S. T.; J. Nanosci. Nanotechnol. 2015, 15, 880 .

13. Xavier-Junior, F. H.; Vauthier, C.; Morais, A. R. V.; Alencar, E. N.; Egito, E. S. T.; Drug Dev. Ind. Pharm. 2017, 43, 700.

14. Tenjarla, S.; Crit. Rev. Ther. Drug Carrier Syst. 1999, 16, 461.

15. Jin, W.; Xu, W.; Liang, H.; Li, Y.; Liu, S.; Li, B. In Emulsions, vol. 3; Grumezescu, A. M., ed.; Academic Press: London, 2016, p. 1. 
16. McClements, D. J.; Soft Matter 2012, 8, 1719.

17. Cho, Y.-H.; Kim, S.; Bae, E. K.; Mok, C. K.; Park, J.; J. Food Sci. 2008, 73, E115.

18. Mekjaruskul, C.; Yang, Y. T.; Leed, M. G. D.; Sadgrove, M. P.; Jay, M.; Sripanidkulchai, B.; Int. J. Pharm. 2013, 445, 1.

19. Fahmy, U. A.; Ahmed, O. A. A.; Hosny, K. M.; AAPS PharmSciTech 2015, 16, 53.

20. Schmalfub, U.; Neubert, R.; Wohlrab, W.; J. Controlled Release 1997, 46, 279.

21. Hegde, R. R.; Verma, A.; Ghosh A.; ISRN Pharm. 2013, 2013, 826798.

22. Komaiko, J. S.; McClements, D. J.; Compr. Rev. Food Sci. Food Saf. 2016, 15, 331.

23. Pachioni-Vasconcelos, J. D. A.; Lopes, A. M.; Apolinário, A. C.; Valenzuela-Oses, J. K.; Costa, J. S. R.; Nascimento, L. D. O.; Pessoa, A.; Barbosa, L. R. S.; Rangel-Yagui, C. O.; Biomater. Sci. 2016, 4, 205.

24. Soni, G. C.; Prajapati, S. K.; Chaudhri, N.; J. Pharm. Sci. Pharmacol. 2014, 3, 410.

25. Lee, D. W.; Marasini, N.; Poudel, B. K.; Kim, J. H.; Cho, H. J.; Moon, B. K.; Choi, H. G.; Yong, C. S.; Kim, J. O.; J. Microencapsulation 2014, 31, 31 .

26. Rodrigues, E. C. R.; Ferreira, A. M.; Vilhena, J. C. E.; Almeida, F. B.; Cruz, R. A. S.; Florentino, A. C.; Souto, R. N. P.; Carvalho, J. C. T.; Fernandes, C. P.; Rev. Bras. Farmacogn. 2014, 24, 699.

27. Moraes, A. R. D. P.; Tavares, G. D.; Rocha, F. J. S.; Paula, E.; Giorgio, S.; Exp. Parasitol. 2018, 187, 12.

28. Xavier-Junior, F. H.; Huang, N.; Vachon, J. J.; Rehder, V. L.; Egito, E. S. T.; Vauthier, C.; Pharm. Res. 2016, 33, 3031.

29. Xavier-Júnior, F. H.; Silva, K. G. H.; Farias, I. E. G.; Morais, A. R. V.; Alencar, E. N.; Araujo, I. B.; Oliveira, A. G.; Egito, E. S. T.; J. Drug Delivery Sci. Technol. 2012, 22, 367.

30. Babushok, V. I.; Linstrom, P. J.; Reed, J. J.; Zenkevich, I. G.; Brown, R. L.; Mallard, W. G.; Stein, S. E.; J. Chromatogr. A 2007, 1157, 414.

31. Xavier-Junior, F. H.; Maciuk, A.; Morais, A. R. V.; Alencar, E. N.; Garcia, V. L.; Egito, E. S. T.; Vauthier, C.; J. Chromatogr. Sci. 2017, 55, 969.

32. Barreto Jr., A. G.; Biscaia Jr., E. C.; Veiga Jr., V. F.; Pinto, A. C.; Carvalhaes, S. F.; Maciel, M. A. M.; Quim. Nova 2005, 28, 719.

33. Veiga Junior, V. F.; Zunino, L.; Patitucci, M. L.; Pinto, A. C.; Calixto, J. B.; J. Pharm. Pharmacol. 2006, 58, 1405.

34. Barbosa, P. C. S.; Medeiros, R. S.; Sampaio, P. T. B.; Vieira, G.; Wiedemann, L. S. M.; Veiga-Junior, V. F.; J. Braz. Chem. Soc. 2012, 23, 1823.

35. Costa, L. S.; Fidelis, G. P.; Cordeiro, S. L.; Oliveira, R. M.; Sabry, D. A; Câmara, R. B. G.; Nobre, L. T. D. B.; Costa, M. S. S. P.; Almeida-Lima, J.; Farias, E. H. C.; Leite, E. L.; Rocha, H. A. O.; Biomed. Pharmacother. 2010, 64, 21.

36. Wang, J.; Zhang, Q.; Zhang, Z.; Li, Z.; Int. J. Biol. Macromol. 2008, 42, 127.
37. Silva, G. D. F.; Silva, S. R. S.; Barbosa, L. C. A.; Duarte, L. P.; Ribeiro, S. M. R.; Queiroz, J. H.; Vieira, S. A.; Oliveira, M. L.; Rev. Bras. Farmacogn. 2009, 19, 530.

38. Marais, M. F.; Joseleau, J. P.; Carbohydr. Res. 2001, 336, 155.

39. Dasgupta, N.; De, B.; Food Chem. 2007, 101, 471.

40. Ponti, V.; Dianzani, M. U.; Cheeseman, K.; Slater, T. F.; Chem.Biol. Interact. 1978, 23, 281.

41. Dias, A. P. S.; Rinaldi, M. C. S.; Moraes, R. M.; Hoehnea 2007, 34, 231.

42. Lyons, K. C.; Charman, W. N.; Miller, R.; Porter, C. J. H.; Int. J. Pharmacol. 2000, 199, 17.

43. Bouchemal, K.; Briançon, S.; Perrier, E.; Fessi, H.; Int. J. Pharmacol. 2004, 280, 241.

44. Aliabadi, H. M.; Elhasi, S.; Mahmud, A.; Gulamhusein, R.; Int. J. Pharmacol. 2007, 329, 158.

45. Dantas, T. N. C.; Silva, H. S. R.; Dantas-Neto, A. A. D.; Marcucci, M. C.; Maciel, M. A. M.; Rev. Bras. Farmacogn. 2010, 20, 368 .

46. Moura, E. C. M.; Souza, A. D. N.; Rossi, C. G. F. T.; Silva, D. R.; Maciel, M. A. M.; Echevarria, A.; Bellieny, M. S. S.; Quim. Nova 2013, 36, 59.

47. Rossi, C. G. F. T.; Scatena Jr., H.; Maciel, M. A. M.; Dantas, T. N. C.; Quim. Nova 2007, 30, 1128.

48. Pereira, J. D. S.; Neri, J. M.; Emerenciano, D. P.; de Freitas, G. R. S.; Felipe, M. B. M. C.; de Souza, M. A. F.; Menezes, F. G.; Maciel, M. A. M.; Quim. Nova 2018, 41, 243.

49. Kabalnov, A. S. In Modern Aspects of Emulsion Science; Binks, B. P., ed.; Royal Society of Chemistry: Cambridge, 1998, ch. 7.

50. Walstra, P.; Chem. Eng. Sci. 1993, 48, 333.

51. Solans, C.; Izquierdo, P.; Nolla, N.; Azemar, N.; Garcia-Celma, M.; Curr. Opin. Colloid Interface Sci. 2005, 10, 102.

52. Everett, D. H.; Basic Principles of Colloid Science; Royal Society of Chemistry: London, 1988.

53. Xue, X.; Cao, M.; Ren, L.; Qian, Y.; Chen, G.; AAPS PharmSciTech 2018, 19, 1847.

54. Neves, J. K. O.; Apolinário, A. C.; Saraiva, K. L. A.; Silva, D. T. C.; Reis, M. Y. F. A.; Damasceno, B. P. G. L.; Pessoa Jr., A.; Galvão, M. A. M.; Soares, L. A. L.; Veiga Jr., V. F.; Silva, J. A.; Converti, A.; Ind. Crops Prod. 2018, 111, 185.

55. Honary, S.; Zahir, F.; Trop. J. Pharm. Res. 2013, 12, 1596.

56. Sharma, S.; Narang, J. K.; Ali, J.; Baboota, S.; Nanotechnology 2016, 27, 375101.

57. Heurtault, B.; Saulnier, P.; Pech, B.; Proust, J.-E.; Benoit, J.-P.; Biomaterials 2003, 24, 4283.

58. Yan, X.; Zhu, P.; Li, J.; Chem. Soc. Rev. 2010, 39, 1877.

59. Hamaker, H. C.; Physica 1937, 4, 1058.

60. Laven, J.; Vissers, J. P. C.; Colloids Surf., A 1999, 152, 345.

61. Fink, J.; Kiely, C. J.; Bethell, D.; Schiffrin, D. J.; Chem. Mater. 1998, 10, 922.

62. Kumar, A.; Joshi, H.; Pasricha, R.; Mandale, A. B.; Sastry, M.; J. Colloid Interface Sci. 2003, 264, 396. 
63. Pellegrino, T.; Kudera, S.; Liedl, T.; Javier, A. M.; Manna, L.; Parak, W. J.; Small 2005, 1, 48.

64. Kaviani, D.; Koonani, M.; Saghi, M.; Bigtan, M. H.; Nanomed. J. 2016, 3, 65 .

65. Mason, T. G.; Graves, S. M.; Wilking, J. N.; Lin, M. Y.; Condens. Matter Phys. 2006, 9, 193.

66. Formariz, T. P.; Chiavacci, L. A.; Scarpa, M. V.; Silva-Júnior, A. A.; Egito, E. S. T.; Terrugi, C. H. B.; Franzini, C. M.; Sarmento, V. H. V.; Oliveira, A. G.; Colloids Surf., B 2010, 77, 47.

67. Loewenberg, M.; Hinch, E. J.; J. Fluid Mech. 1997, 338, 299.

68. Tardos, T. F.; Izquierdo, P.; Esquena, J.; Solans, C.; Adv. Colloid Interface Sci. 2004, 108, 303.

69. Yuyama, H.; Watanabe, T.; Ma, G.-H.; Nagai, M.; Omi, S.; Colloids Surf., A 2000, 168, 159.
70. Sugiura, S.; Nakajima, M.; Iwamoto, S.; Seki, M.; Langmuir 2001, 17, 5562.

71. Tripathi, S.; Kushwah, V.; Thanki, K.; Jain, S.; Nanomedicine: NBM 2016, 12, 1431.

72. Mishra, B.; Patel, B. B.; Tiwari, S.; Nanomedicine: NBM 2010 , 6, 9.

73. Saso, L.; Firuzi, O.; Curr. Drug Targets 2014, 15, 23.

74. Hu, M.-L.; Chang Gung Med. J. 2001, 34, 449.

75. Wang, S.; Su, R.; Nie, S. F.; Sun, M.; Zhang, J.; Wu, D. Y.; Moustaid-Moussa, N.; J. Nutr. Biochem. 2014, 25, 363.

Submitted: April 17, 2018

Published online: September 4, 2018 